\title{
Electrical conductivity of lithium tantalate thin film
}

\section{(Condutividade elétrica de filme fino de tantalato de lítio)}

\author{
S. I. Gudkov ${ }^{1}$, A. V.Solnyshkin ${ }^{1,2}$, D. A. Kiselev ${ }^{3}, A$. N. Belov ${ }^{2 *}$ \\ ${ }^{I}$ Tver State University, Department of Condensed Matter Physics, Tver, Russia \\ ${ }^{2}$ National Research University of Electronic Technology “MIET”, Department of Integral Electronics \\ and Microsystems, Shokin Square 1, Zelenograd 124498, Moscow, Russia \\ ${ }^{3}$ National University of Science and Technology “MISiS”, Department of Materials Science of Semiconductors \\ and Dielectrics, Moscow, Russia
}

\begin{abstract}
The electrical conductivity of lithium tantalate thin film on the silicon substrate was studied. The film structure was prepared by RF magnetron sputtering. In general, the current-voltage characteristics were asymmetric and similar to that of a diode. The currentvoltage characteristics had several sections associated with various transport mechanisms of current carriers. The main conductivity mechanism was related to the space-charge-limited current. The current-voltage characteristics showed that there was a mismatch between the forward and backward runs. One of the reasons for such behavior is a space charge accumulation due to charge carriers which were injected from the electrode and did not relax.
\end{abstract}

Keywords: lithium tantalate, electrical conductivity, thin film.

\section{Resumo}

A condutividade elétrica de filme fino de tantalato de lítio sobre substrato de silício foi estudada. A estrutura de filme foi preparada por pulverização por magnétron RF. Em geral as características de corrente-tensão foram assimétricas e similares às de um diodo. As características de corrente-tensão tiveram várias seções associadas a vários mecanismos de transporte de portadores de corrente. $O$ principal mecanismo de condutividade foi relacionado à corrente limitada por carga espacial. As características de correntetensão mostraram que havia incompatibilidade entre as conduções avante e a ré. Uma das razões para esse comportamento é um acúmulo de carga espacial devido aos portadores de carga que foram injetados no eletrodo e não relaxaram.

Palavras-chave: tantalato de lítio, condutividade elétrica, filme fino.

\section{INTRODUCTION}

Lithium tantalate $\left(\mathrm{LiTaO}_{3}\right.$ or $\left.\mathrm{LT}\right)$ is an important ferroelectric material for applications in acousto- and optoelectronics, frequency modulators, and transducers [16]. The Curie temperature of lithium tantalate is $880 \mathrm{~K} \mathrm{[5].}$ Lithium tantalate has a perovskite-like crystal structure, such as lithium niobate $\left(\mathrm{LiNbO}_{3}\right)$. As opposed to lithium niobate, some properties of $\mathrm{LiTaO}_{3}$ were not studied so well. Currently, there is also a trend to miniaturize electronic devices and to integrate various functional materials with silicon technologies [7]. In this regard, it is attractive to integrate crystalline ferroelectric materials, in particular lithium tantalate, into thin film heterostructures based on a silicon wafer [8-13].

Manufacturing the thin film structures based on the lithium tantalate is complicated by the high melting point that is about $1920 \mathrm{~K}$. The production of high-quality films

*becauseimaphysicist@gmail.com

Dhttps://orcid.org/0000-0003-0634-4878 of $\mathrm{LiTaO}_{3}$ requires complex and expensive equipment [5, 10]. In addition, complex stoichiometric quantifications are required for characterizations of the films of lithium tantalate. These problems make difficulties in the production of thin films based on $\mathrm{LiTaO}_{3}$. Thin film heterostructures based on this ferroelectric are deposited by various methods such as chemical solution deposition (CSD), metal-organic chemical vapor deposition (MOCVD), RF sputtering, and pulsed-laser ablation deposition (PLAD) [5]. There are problems with the reproducibility of many physical properties. Thin film properties can depend on many manufacturing factors like quality and type of silicon substrates, method of ferroelectric layer deposition, the atmosphere in the deposition chamber, and others. At the present time, the high-quality thin films of lithium tantalate cannot be guaranteed despite the extremely resource-demanding manufacturing. In this study, lithium tantalate thin films were produced by high-frequency magnetron sputtering. This method allows for depositing the best quality thin film structures. Also, we studied properties, in particular, electrical properties of lithium tantalate thin films deposited on silicon substrates. 


\section{EXPERIMENTAL}

Experimental samples were deposited by means of magnetron spattering in a SUNPLA 40TM vacuum chamber (Korea). A Z-cut lithium tantalate plate attached to a copper base was used as a target. The deposition was carried out in plasma of oxygen $(40 \mathrm{vol} \%)$ and argon $(60 \mathrm{vol} \%)$ at a pressure of $4.3 \times 10^{-3}$ torr and a magnetron power of $150 \mathrm{~W}$ on a p-type silicon substrate of (111) orientation. The substrate was previously cleaned with an ion gun for $5 \mathrm{~min}$. During the film deposition process, the substrate rotation speed was 2 $\mathrm{rpm}$. After the film growth, the heterostructure $\mathrm{LiTaO}_{3} / \mathrm{Si}$ was annealed twice. Both annealing processes were performed into a resistance heating furnace. The first annealing was carried out at $550^{\circ} \mathrm{C}$ for $1 \mathrm{~h}$ in air. The second annealing was carried out at $700{ }^{\circ} \mathrm{C}$ for $1 \mathrm{~h}$ in the air also. The ferroelectric layer thickness measured by the $\boldsymbol{\alpha}$-SETM ellipsometer (J.A. Woollam, USA) was $150 \pm 1 \mathrm{~nm}$.

The X-ray diffraction analysis of the $\mathrm{LiTaO}_{3}$ film was made with a DRON 3 diffractometer using $\mathrm{CuK} \alpha$ radiation. The surface morphology, as-grown domain structure, and local piezoelectric hysteresis loops of the samples were characterized by the piezoresponse force microscopy (PFM) method using a scanning probe microscope MFP-3D (Asylum Res., USA) with Ti/Ir coated conductive probes (Asyelec-02, Asylum Res., USA). AC voltage $\left(2 \mathrm{~V}_{\mathrm{pp}}\right)$ was superimposed onto a triangular square-stepping wave $(\mathrm{f}=0.5 \mathrm{~Hz}$, with writing and reading times of $25 \mathrm{~ms}$, and bias window up to $\pm 50 \mathrm{~V}$ ) during the remnant piezoelectric hysteresis loop measurements. To estimate effective $d_{33}$ piezoelectric constant, the deflections and vibration sensitivity of the cantilever alignment were calibrated by GetReal procedure using IgorPro software (Asylum Res., USA). For electrical measurements, a top silver electrode with a diameter of $4.7 \pm 0.1 \mathrm{~mm}$ was deposited on the $\mathrm{LiTaO}_{3}$ film-free surface. The bottom electrode was the silicon wafer. Since voltage was applied to the top and bottom electrodes, the working volume of the film was limited by the area of the top electrode. DC electrical conductivity of ferroelectric heterostructures was carried out with an immittance meter E7-20. The applied DC voltage varied from -5 to $+5 \mathrm{~V}$ in the step of $0.02 \mathrm{~V}$. The applied voltage was considered positive when a positive potential was applied to the top electrode, and conversely.

\section{RESULTS AND DISCUSSION}

To determine the structure of the $\mathrm{LiTaO}_{3}$ film, X-ray diffraction (XRD) measurements were carried out. The XRD pattern of this film is presented in Fig. 1. The structure was studied at room temperature. An amorphous structure was mainly revealed for the film without annealing, since the reflexes were very weak or not observed at all. The crystal structure in the $\mathrm{LiTaO}_{3}$ film was observed when it was annealed. The spontaneous polarization of $\mathrm{LiTaO}_{3}$ is directed along [001]. According to the XRD data, spontaneous polarization in the film structure is directed at an angle to the substrate, i.e., there are in-plane and out-of-plane components

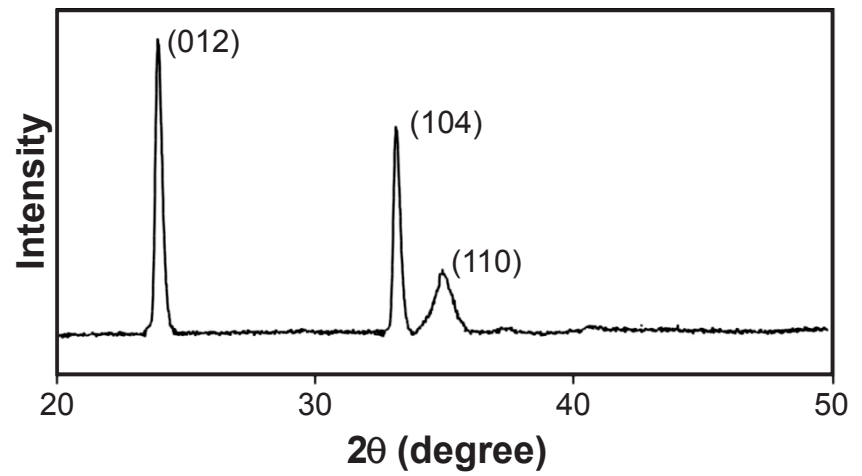

Figure 1: X-ray diffraction pattern for the $\mathrm{LiTaO}_{3}$ thin film. [Figura 1: Padrão de difração de raios $\mathrm{X}$ do filme fino de $\mathrm{LiTaO}_{3}$.]

of the spontaneous polarization.

The atomic force microscopy (AFM) characterization showed that RF magnetron sputtering produced continuous
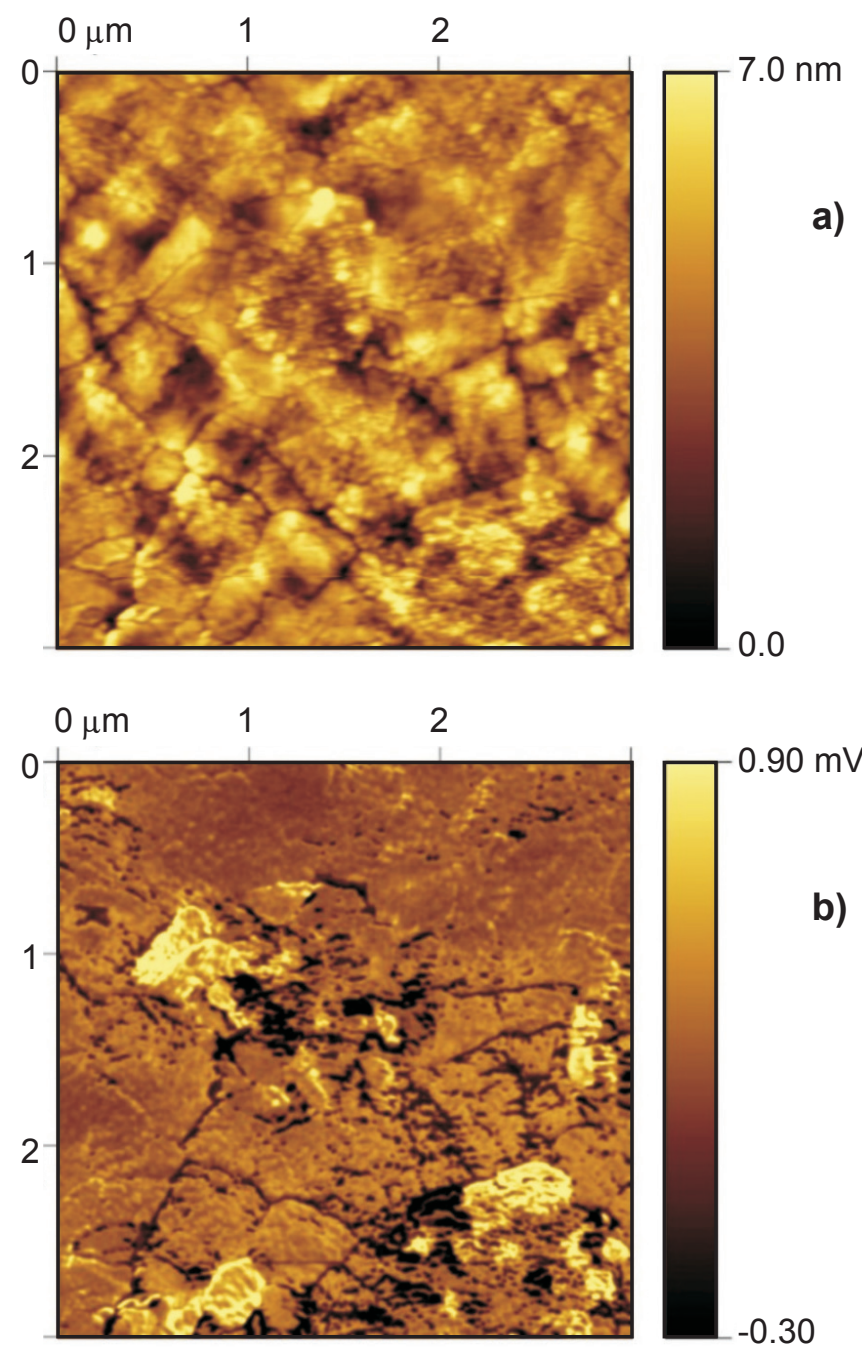

Figure 2: Surface image of $\mathrm{LiTaO}_{3}$ thin film obtained by the AFM method (a) and surface distribution of the vertical component of the piezoelectric response revealed by piezoelectric force microscopy (b). [Figura 2: Imagem da superfície do filme fino de $\mathrm{LiTaO}_{3}$ obtida pelo método AFM (a) e distribuição superficial do componente vertical da resposta piezelétrica revelada por microscopia de força piezelétrica $(b)$.] 
$\mathrm{LiTaO}_{3}$ film (Fig. 2a). The lithium tantalate film deposited on a silicon wafer had a grain structure and a slight roughness. Individual grains exhibited a noticeable piezoelectric response (Fig. 2b). The contrast in Fig. 2b is associated with the amplitude and direction of the local piezoelectric response determined by spontaneous polarization.

The remnant loop of the $\mathrm{LiTaO}_{3}$ thin film was measured using switching spectroscopy PFM (SS-PFM). Hysteresis in PFM may be fundamentally different than hysteresis in a macroscopic sample (Fig. 3). Local PFM hysteresis loops observed indicated ferroelectric polarization switching at nanoscale for the sample studied. PFM hysteresis loops were distinctly asymmetric along the axis Y. According to [14], this offset is mainly attributed to the electrostatic effect. Moreover, the local PFM hysteresis loops account for the polarization switching process in a nanoscale, just below the tip. Therefore, intrinsic polarization in the nanoregion may also contribute to the offset and asymmetry of the local piezoresponse hysteresis loops [15].

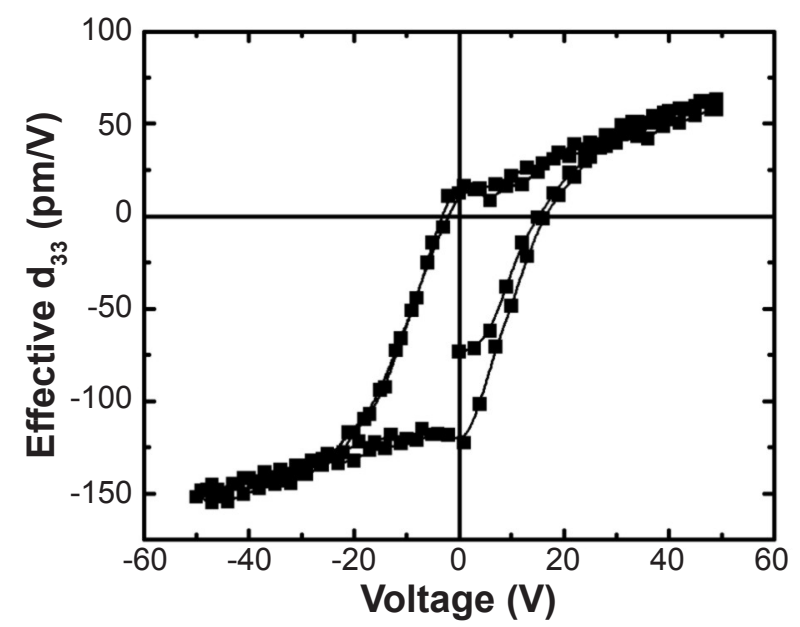

Figure 3: Local hysteresis loops obtained by piezoelectric force microscopy for the $\mathrm{LiTaO}_{3}$ thin film.

[Figura 3: Curvas de histerese obtidas por microscopia de força piezelétrica do filme fino de $\mathrm{LiTaO}_{3}$.]

For some devices with ferroelectric functional elements, an electric field must be applied to control the element operation. At the electric field applied to ferroelectric films, leakage currents occur. These currents have a significant effect on the practically important properties of ferroelectrics. There is a negative impact on the working efficiency of ferroelectric devices such as non-volatile ferroelectric memory, acousto- and optoelectronic devices, transducers, and others. Leakage currents depend on the film thickness, annealing conditions, structure defects, electrode material, and grain size of the film [8]. Therefore, the study of the conductivity mechanisms causing the leakage currents in ferroelectric thin films of lithium tantalate is quite important. In particular, revealing the charge transfer mechanisms in $\mathrm{LiTaO}_{3}$ thin films is necessary for improving the ferroelectric functional element stability. Fig. 4a shows current density curves versus the DC voltage applied to the $\mathrm{LiTaO}_{3}$ film sample. The current-voltage characteristic was asymmetrical and diode-like. At the negative voltage applied to the film structure, the conduction was lower (curves 1 and 2) than at the positive voltage (curves 3 and 4). When a positive potential was applied to the top electrode, there was a region with a rapid increase in the current density. It may indicate the charge carrier injection from the electrode through the space-charge region or the switching polarization in the ferroelectric domains of the $\mathrm{LiTaO}_{3}$ layer. The conductivity of the thin film heterostructure was determined from the initial section of the current-voltage characteristic. It was equal to $(8.07 \pm 0.39) \times 10^{-11}(\Omega . m)^{-1}$. The current-voltage (I-V) characteristic presented in the semilogarithmic scale has several sections (Fig. 4b) that may indicate the dominance of different conduction mechanisms in certain intervals of the applied electric field. Fig. $4 \mathrm{~b}$ shows that the forward and backward runs did not coincide (curves 1 and 2) when a negative voltage was applied to the thin film structure. Therefore, the dominant conduction mechanisms were determined for each run individually. Such a behavior
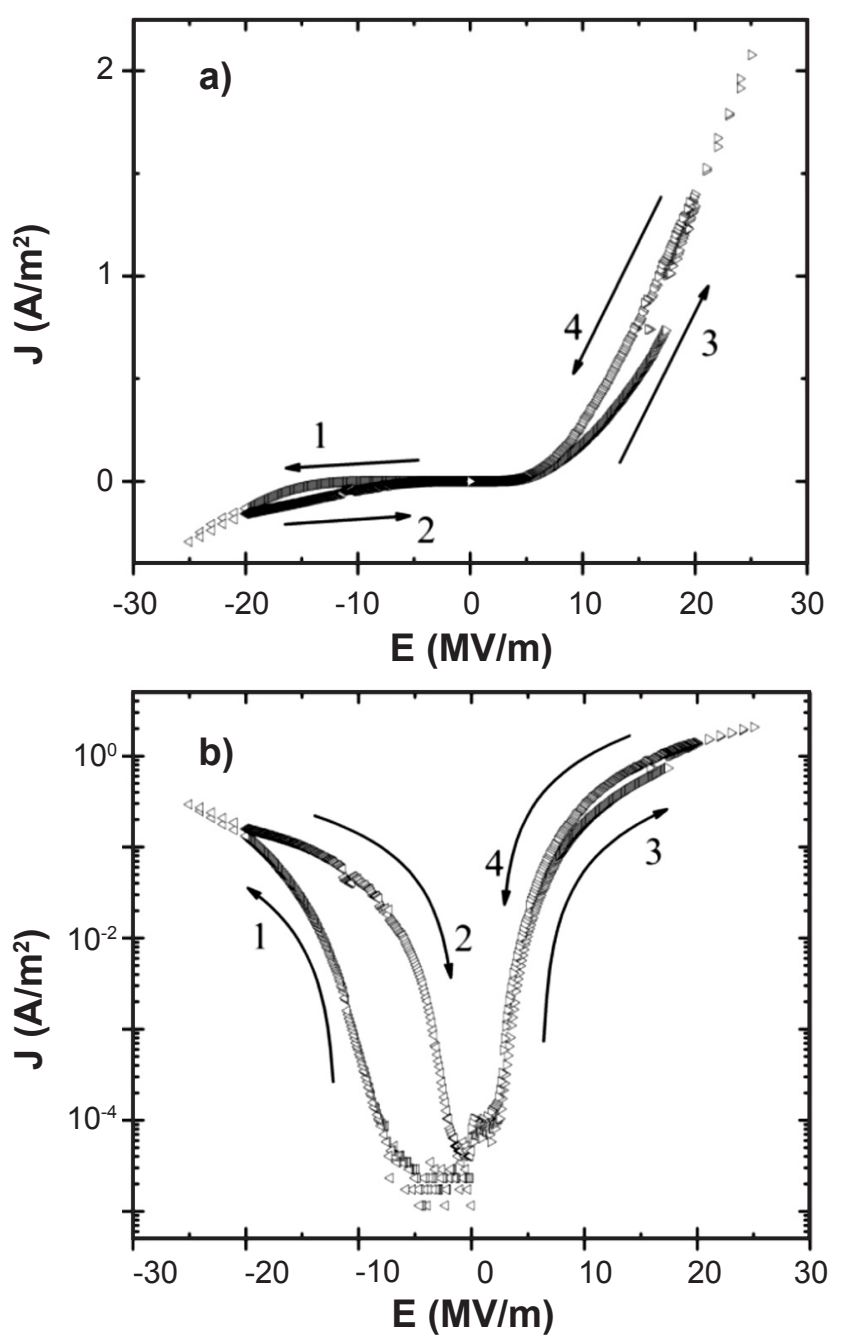

Figure 4: Current-voltage characteristic in linear (a) and semilogarithmic (b) scale for the $\mathrm{Ag} / \mathrm{LiTaO}_{3} / \mathrm{Si}$ structure.

[Figura 4: Curva corrente-tensão em escala linear (a) e semilogarítmica (b) para a estrutura $\mathrm{Ag} / \mathrm{LiTaO} / \mathrm{Si}$.] 
of the I-V characteristics may indicate that the electrical charges injected from the electrode into the lithium tantalate thin film did not relax during the measurement time. It led to the current density increase at the backward run (curve 2). Similar effects are observed in memristor structures $[16$, 17].

It is known there are several conductivity mechanisms in thin ferroelectric films on various substrates $[18,19]$. The Schottky effect is the charge carriers' emission from a conductive electrode into a dielectric or semiconductor film. It occurs due to their thermal transfer over a potential barrier under an electric field applied to the thin film structure. This effect is described by the following equation [20]:

$$
J=A^{*} \cdot T^{2} \cdot \exp \left[-\frac{\mathrm{e}}{\mathrm{k} \cdot \mathrm{T}}\left(\phi_{\mathrm{B}}{ }^{-} \sqrt{\frac{\mathrm{e} \cdot \mathrm{E}}{4 \cdot \pi \cdot \varepsilon_{0} \cdot \varepsilon_{\mathrm{r}}}}\right)\right]
$$

where $\mathrm{J}$ is the current density, $\mathrm{A}^{*}$ the Richardson's effective constant, $\mathrm{T}$ the temperature, e the elementary charge, $\mathrm{k}$ the Boltzmann constant, $\phi_{\mathrm{B}}$ the potential barrier height, $\mathrm{E}$ the electric field strength, $\varepsilon_{0}$ the electric constant, and $\varepsilon_{\mathrm{r}}$ the high-frequency (optical) dielectric constant; the Schottky effect belongs to interface-controlled mechanisms. Another mechanism is based on the Poole-Frenkel effect. This mechanism consists of decreasing the trap potential barrier height for the charge carriers, thus leading to an increase in the number of free charge carriers. According to this mechanism, the current density is determined by [20]:

$$
\mathrm{J}=\mathrm{e} \cdot \mu \cdot \mathrm{N}_{\mathrm{C}} \cdot \operatorname{E} \cdot \exp \left[-\frac{\mathrm{e}}{\mathrm{k} \cdot \mathrm{T}}\left(\phi_{\mathrm{B}}{ }^{-} \sqrt{\frac{\mathrm{e} \cdot \mathrm{E}}{4 . \pi \cdot \varepsilon_{0} \cdot \varepsilon_{\mathrm{r}}}}\right)\right]
$$

where $\mu$ is the charge mobility and $N_{C}$ the effective density of states in the conduction band; the Poole-Frenkel effect belongs to bulk-controlled mechanisms. The last of the main mechanisms of charge transfer in thin dielectric films is space-charge-limited current. This effect consists in the appearance of a space charge injected into the film. This space charge affects the electrical conductivity of the thin film structure. These currents obey Mott's square law [21]:

$$
\mathrm{J}=\frac{9}{8} \varepsilon_{0} \cdot \varepsilon_{\mathrm{r}} \cdot \mu \frac{\mathrm{U}^{2}}{\mathrm{~d}^{3}}
$$

where $d$ is the sample thickness. The study of the charge transfer mechanisms in the samples was analyzed on the base of graphical plots. To this end, the current-voltage $(\mathrm{I}-\mathrm{V})$ characteristics were presented in the coordinates corresponding to each of the thin film conduction mechanisms: Schottky effect, $\ln J \sim E^{1 / 2}$; Poole-Frenkel effect, $\ln (\mathrm{J} / \mathrm{E}) \sim \mathrm{E}^{1 / 2}$; and space-charge-limited current, J $\sim \mathrm{E}^{2}$ [20-23]. On the base of straight sections on the corresponding curves, it was concluded about the dominance of certain conduction mechanism. The transport mechanisms of current carriers dominating in each interval were found using the I-V characteristics replotted in the Schottky, Poole-Frenkel, and space-charge-limited current coordinates. The curves corresponding to each mechanism are shown in Fig. 5. It
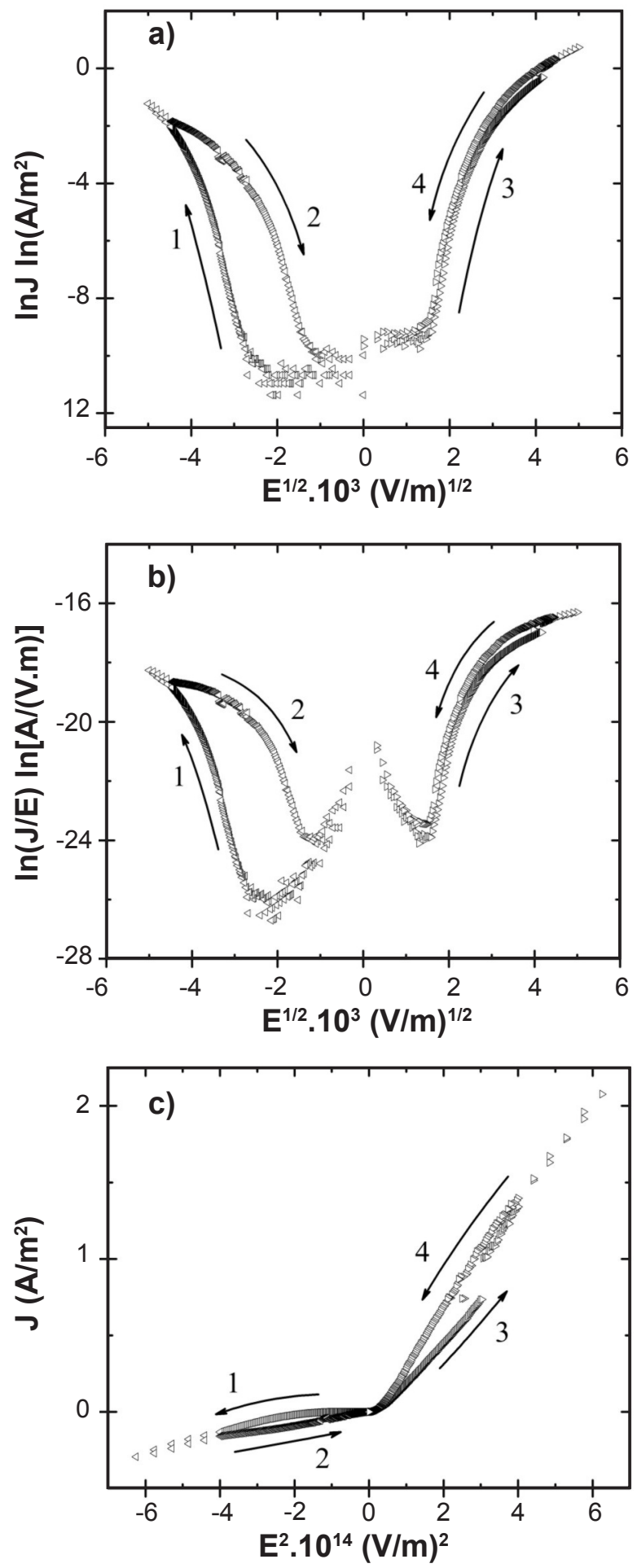

Figure 5: Current-voltage characteristics in Schottky (a), PooleFrenkel (b), and space-charge-limited current (c) presentations for the $\mathrm{Ag} / \mathrm{LiTaO}_{3} / \mathrm{Si}$ structure.

[Figura 5: Curvas corrente-tensão nas representações de Schottky (a), Poole-Frenkel (b) e corrente limitada por carga espacial (c) para a estrutura $\mathrm{Ag} / \mathrm{LiTaO}_{3} / \mathrm{Si}$.]

was found, at low electric field strengths up to $\sim 5 \mathrm{MV} / \mathrm{m}$, the current-voltage characteristic corresponded to Ohm's law. At the voltage increase, the main conduction mechanism in the lithium tantalate thin film became the space-charge- 
limited current at both the positive and negative potential applied to the top electrode. However, the conduction mechanism corresponding to the space-charge-limited current had different field intervals for negative voltage. This charge transfer was observed during the forward run in the electric field strength from 15 to $25 \mathrm{MV} / \mathrm{m}$ (Fig. $4 \mathrm{~b}$, curve 1) and the backward run from 25 to $4 \mathrm{MV} / \mathrm{m}$ (Fig. $4 \mathrm{~b}$, curve 2). One can assume that charges were injected into the thin film of $\mathrm{LiTaO}_{3}$ under the high electric field. During the voltage decrease (curve 2), the injected charges increased the sample conductivity and remained in the thin film bulk until vanishing the applied field. The Schottky effect and the Poole-Frenkel effect did not contribute to the electrical conductivity considerably. However, for the ferroelectric film structures based on lead titanate zirconate, the PooleFrenkel or Schottky effects may dominate other mechanisms $[24,25]$. Moreover, the dominance of the space-chargelimited currents does not contradict studies of leakage currents in thin film ferroelectric structures $[19,26]$.

\section{CONCLUSIONS}

The lithium tantalate thin film was deposited on a singlecrystal silicon substrate by RF magnetron sputtering. The ferroelectric $\mathrm{LiTaO}_{3}$ layer was polycrystalline and continuous. It was found that the film had a noticeable local piezoelectric response. Local PFM hysteresis loops were observed. It indicated ferroelectric polarization switching at nanoscale for the lithium tantalate thin film. Also, we have studied the conductive properties of $\mathrm{Ag} / \mathrm{LiTaO}_{3} / \mathrm{Si}$ heterostructure. The structure was weakly conducting in electric fields below 5 $\mathrm{MV} / \mathrm{m}$. The current-voltage characteristic was diode-like. When the electric field was directed from the substrate to the top electrode, the behavior of electric current had a certain feature. At voltage increasing, the conductivity was lower than one at voltage decreasing. There was a mismatch in the forward and backward run of the current dependencies on the bias. It may be due to the charge injected from the electrode into the $\mathrm{LiTaO}_{3}$ film. These charges did not relax during the electric field decrease. The main transfer mechanism of charge carriers was the space-charge-limited current under high electric fields. The Schottky effect appeared in the structure with a depletion layer due to the potential barrier for majority carriers. It belongs to interfacecontrolled mechanisms. If the bias field is applied oppositely to the junction field, the potential barrier decreases, and the film is enriched in the majority carriers. The space-chargelimited currents are related to charge accumulation. The coexistence of the Schottky effect and space-charge-limited currents in one structure is quite possible. However, only one of them (the space-charge-limited current) is dominant, while the other makes an extremely small contribution to the electrical conductivity of the sample. The Poole-Frenkel effect consists in decreasing the trap potential barrier height for the charge carriers in bulk. For low bias fields, there was no considerable increase in charge carriers due to the Poole-Frenkel effect. In our case, the threshold field was about $4 \mathrm{MV} / \mathrm{m}$. Thus, there is the Poole-Frenkel effect under sufficiently high electric fields in semiconductors and dielectrics. However, despite the high electric fields applied to the lithium tantalate film (up to $30 \mathrm{MV} / \mathrm{m}$ ), the contribution of the Poole-Frenkel effect was less than spacecharge-limited currents.

\section{ACKNOWLEDGMENT}

This work was supported by the Russian Science Foundation (Grant No. 15-19-00138).

\section{REFERENCES}

[1] D.N. Nikogosyan, Nonlinear optical crystals: a complete survey, Springer-Verlag, New York (2005).

[2] F. Juvalta, M. Jazbinšek, P. Günter, K. Kitamura, J. Opt. Soc. Am. B 23, 2 (2006) 276.

[3] I. Torchinsky, G. Rosenman, Appl. Phys. Lett. 92 (2008) 52903.

[4] S. Huband, D.S. Keeble, N. Zhang, A.M. Glazer, A. Bartasyte, P.A. Thomas, J. Appl. Phys. 121 (2017) 24102.

[5] V.Ya. Shur, in "Advanced piezoelectric materials", K. Uchino (Ed.), 2 ${ }^{\text {nd }}$ ed., Elsevier (2017) 235.

[6] C. Chatterjee, D. Miller, I. Ostrovskii, in Proc. Mtgs. Acoust. 33 (2018) 65001.

[7] J.F. Scott, Science 315, 5814 (2007) 954.

[8] D.-Y. Zhang, K. Li, W.-D. Peng, J.-S. Xie, W. Qian, Int. J. Mechatron. Autom. 2, 4 (2012) 295.

[9] V. Stenger, M. Shnider, S. Sriram, D. Dooley, M. Stout, Proc. SPIE 8261 (2012) 82610Q.

[10] Irzaman, Y. Pebriyanto, E.R. Apipah, I. Noor, A. Alkadri, Integr. Ferroelectr. 167, 1 (2015) 137.

[11] B. Sun, D. Pan, Z. Huang, J. Wang, Y. Jiang, Proc. SPIE 9686 (2016) 968611.

[12] D. Pan, J. Wang, B. Sun, J. Gou, Mater. Res. Express 4 (2017) 26402.

[13] Irzaman, R. Siskandar, N. Nabilah, Aminullah, B. Yuliarto, K.A. Hamam, H. Alatas, Ferroelectrics 524, 1 (2018) 44.

[14] S. Jesse, H.N. Lee, S.V. Kalinin, Rev. Sci. Instrum. 77 (2006) 73702.

[15] H. Qiao, C. He, F. Zhuo, Z. Wang, X. Li, Y. Liu, X. Long, Ceram. Int. 44, 16 (2018) 20417.

[16] S.G. Hu, S.Y. Wu, W.W. Jia, Q. Yu, L.J. Deng, Y.Q. Fu, Y. Liu, T.P. Chen, Nanosci. Nanotech. Let. 6, 9 (2014) 729.

[17] S. Vaidyanathan, C. Volos (Ed.), "Advances in memristors, memristive devices and systems", Springer Int. (2017).

[18] L. Pintilie, in "Ferroelectrics: physical effects", M. Lallart (Ed.), InTech (2011) 101.

[19] A. Sigov, Yu. Podgorny, K. Vorotilov, A. Vishnevskiy, Phase Transit. 86, 11 (2013) 1141.

[20] F.-C. Chiu, Adv. Mater. Sci. Eng. 2014 (2014) 578168.

[21] M.A. Lampert, P. Mark, Current injection in solids, Acad. Press, New York (1970).

[22] S.M. Sze, Semiconductor devices, physics and 
technology, John Wiley Sons (2002).

[23] A.V. Solnyshkin, A.S. Troshkin, A.A. Bogomolov, I.P. Raevski, D.N. Sandjiev, V.Yu. Shonov, Integr. Ferroelectr. 106 (2009) 61.

[24] M.V. Kamenshchikov, A.V. Solnyshkin, A.A. Bogomolov, I.P. Pronin, Phys. Solid State 53 (2011) 2080.
[25] K. Liang, A. Buditama, D. Chien, J. Cui, P.L. Cheung, S. Goljahi, S.H. Tolbert, J.P. Chang, C.S. Lynch, J. Appl. Phys. 117 (2015) 174107.

[26] A. Jamil, M.A. Rafiqa, Ceram. Int. 44, 18 (2018) 22574.

(Rec. 30/11/2019, Rev. 11/12/2019, 08/03/2020, Ac. $22 / 03 / 2020)$ 